\title{
On the discussion about Zhi Dao between Confucius and Lao-tzu in Zhuangzi
}

\author{
Pengcheng Han
}

Department of Philosophy, and Religious Studies, Peking University, China

Keywords: Confucius; Lao-tzu; Zhi Dao.

\begin{abstract}
Based on the materials about Confucius meeting with Lao-tzu in Zhuangzi, this paper studies about their discussion about Zhi Dao (the regulation of the courses). The strategy of Confucius on Zhi Dao is expounded, and the criticism from Lao-tzu on that is analyzed, as well as Lao-tzu's further proposition on Zhi Dao.
\end{abstract}

\section{Introduction}

The meeting of Confucius and Lao-tzu is recoded in many historical documents such as the Records of Grand Historian (Shiji), the Queries of Zeng-Tzu (Zeng-tzu Wen) and Zhuangzi. As two saints in traditional ionosphere, both Confucius and Lao-tzu had left their later generation's abundant heritage of philosophical thoughts. Founded by Confucius and Lao-tzu respectively, the two schools of Confucianism and Taoism had many debates and disputes over ideology in history. As for the direct ideological controversy between Confucius and Lao-tzu on their conversations 2500 years ago, the 5 volumes of Chuang-Tzu (Heaven and Earth, The Way of Heaven, The Revolution of Heaven, Tian Zi-fang and Knowledge Rambling in the North) have 8 chapters covered their meeting, and there are 7 chapters that is about their discussion. Despite the ideological inclination of the writers, the literature still presents readers with the abundant and vigorous thoughts of Confucius and Lao-tzu. The context of the 7 chapters is mainly about Dao (Tao), Zhi Dao (the regulation of the courses) and Renyi (benevolence and righteousness), this paper primarily studies about the discussion on Zhi Dao.

\section{Confucius: 'To Zhi Dao is to follow'.}

The phrase Zhi Dao (as how to be enlightened) here is from The Heaven and Earth, Zhuangzi, where Confucius was consulting Lao-tzu [1]. In the 9th chapter of the heaven and Earth, Confucius and Lao-tzu had a conversation on this topic [2]. Although the contexts in Zhuangzi presents a scene of Lao-tzu preaching Confucius, in a way it reveals their controversy and debate in perspective of ideology. Confucius firstly states his approach to Zhi Dao:

Confucius asked Lao-tzu, saying, 'some men Zhi Dao (regulate their course), which they have only to follow (a thing, they say,) what is admissible or it is inadmissible; it is so, or it is not so. (They are like) the sophists who say that they can distinguish what is hard and what is white as clearly as if the objects were houses suspended in the sky. Can such men be said to be sages' [3].

Guoxiang annotated that in Confucius's opinion, the approach to Zhi Dao is to follow or to imitate [4]. Here Confucius believes that the key to Zhi Dao is to learn. As for what is to be learned, Guoxiang interpreted it as to force inadmissible into admissible, and to turn wrong into right [5]. But actually Guoxiang's comprehension here is slightly biased. In chapter The Floods of Autumn in Zhuangzi, Gong-sun Long said:

I brought together the views that agreed and disagreed; I considered the questions about hardness and whiteness; I set forth what was allowable and what was not, and what was to be affirmed and what was not [6].

Gong-sun Long claimed himself to be a student of Wei Mou (princess of Wei) since his childhood, and he reached his accomplishment as Wei Mou's compliment that (he) has enough wisdom to know where the discussions about what is right and what is wrong should end [7]. 
Gong-sun Long may not compare with Zhuang-tzu, but nor does he completely deviate from Zhuang-tzu's theory. In addition, the statement of agreed and disagreed, hardness and whiteness, affirmed and what was not, what was allowable and what was not here should be consistent as in one view. Therefore, Confucius' words here should be interpreted as admissible or inadmissible, affirmed or not affirmed. The former is an ethical criterion to measure whether people's behavior is appropriate, the latter is to indicate the property of things. While the statement of the sophists as 'to distinguish what is hard and what is white as clearly as if the objects were houses suspended in the sky' here should be construed in the way that the two verdicts should be distinct and obvious [8]. Hence the Zhi Dao of Confucius can be decomposed as two parts: the approach of learning as to follow or to imitate and the accomplishment of learning so as to make distinguished judgment. In Analects:

Duke Ai asked which of the disciples loved to learn. Confucius replied to him, “There was Yan Hui, he loved to learn. He did not transfer his anger; he never repeat a fault. Unfortunately, his appointed time was short and he died; and now there is not such another. I have not yet heard of anyone who loves to learn as he did" [9].

The Master said, "The superior man, extensively studying all learning, and keeping himself under the restraint of the rules of propriety, may thus likewise not overstep what is right" [10].

The Master said, "With sincere faith he unites the love of learning; holding firm to death, he is perfecting the excellence of his course. Such one will not enter a tottering state, nor dwell in a disorganized one. When right principles of government prevail in the kingdom, he will show himself; when they are prostrated, he will keep concealed. When a country is well governed, poverty and a mean condition are things to be ashamed of. When a country is illy governed, riches and honor are things to be ashamed of" [11].

Confucius defined that a studious person should be like his disciple Yan Hui who did not transfer his anger nor repeat a fault, and thus Yan Hui knew what is admissible and what is not, and then he would carry out (what is admissible). Confucius deemed that one should firstly be literarily erudite and morally self-disciplined, then one cannot violate Dao(as ethical standards) [12]. Confucius also said that if you do not learn the rules of Propriety, your character cannot be established. According to Analects, Confucius believed that things to be learned in pursuit of Zhi Dao should be traditional rites or rules of propriety. As in The Book of Music in The Book of Rites, "the happiness is generated inside of a man while the rules of propriety are imposed on by external factors". In Confucius' opinion, to learn is in order to be capable of making judgments, especially in accord with the third quote above that only by knowing what is affirmable can one tell whether a country is tottering and whether right principles of government prevail in the country; only by knowing what is admissible can one make his decision of whether to enter a state, whether to dwell and whether to live in seclusion.

In Confucius's theory, there are two things to be imitated or to be learned: record documents and living sages. As in Analects:

The Master said, "I could describe the ceremonies of the Xia dynasty, but the Qi cannot sufficiently attest my words. I could describe the ceremonies of the Yin dynasty, but Song cannot sufficiently attest my words. (They cannot do so) because of the insufficiency of their records and wise men. If those were sufficient, I could adduce them in support of my words" [13].

Hence we can conclude that, according to Confucius, things to be learned in pursuit of Zhi Dao is $\mathrm{Li}$ (traditional ceremony) or rules of propriety [14]. In addition, Confucius pointed out two approach to obtain the knowledge of traditional ceremony: records and wise men. However, either consulting records or wise men is to follow established standards and benchmarks so as to be informed of what is admissible or not and what is affirmable or not. Additionally, as a law of standard and order, Li is in fact defining what is admissible and what is affirmable. By learning Li one can reach the level of Zhi Dao (be enlightened). 


\section{Lao-tzu: 'One who has forgotten himself has become identified with Heaven.'}

Lao-tzu disagreed with Confucius and he considered the so-called Zhi Dao scholars of Confucius was like the busy underlings of a court, who toil their bodies and distress their minds with their various artifices [15]. Lao-tzu rejected Confucius from three aspects and he gave his approach to Zhi Dao: to forget oneself inwardly. Lao-tzu criticized Confucius's approach to Zhi Dao, he thought both judgments like admissible or not and affirmable or not had their own problems.

(That is just like) tied-up dogs sorrow in vain, or monkeys that are brought from their forests (for their trickiness) [16].

(Dao) is not in their movements or stoppages, their dying or living, their falling or rising again, (Dao) is not to be found neither to be explored [17].

Guoxiang annotated that both tied-up dogs sorrow in vain and monkeys that are brought from their forests are descriptions of abnormal phenomenon [18]. Because in Lao-tzu's point of view, the judgment of what is admissible is like a collar used to constrain hounds due to their instinct of running, and monkeys got captured because of their gift to move swiftly through jungles. There is a mutual tensile force between what is admissible and the inner essence of human, which manifests as restraint and temptation, and consequently the essence of human vanishes. In a changing world, everything stops right at where it begins to move, dies when it comes into being, falls when it begins to rise, and everything that has a shape actually does not have a fixed outline. Therefore, to make verdicts like what is affirmable about any entity is a mistake itself. As in the 2nd chapter of Laozi:

All in the world recognize the beautiful as beautiful. Herein lies ugliness. All recognize the good as good. Herein lies evil.

(Therefore)Presence and absence produce each other. Difficulty and ease bring about each other. Long and short delimit each other. High and low rest on each other. Sound and voice harmonize each other. Front and back follow each other [19].

In Su Zhe's comprehension of this chapter, he interpreted that most people judge beauty or ugliness by appearance, their so-called beauty and good are not what's really beautiful and good. Those people have no idea of presence and absence, they don't know that long and short, easy and hard, high and low, loud and tranquil, front and back are relative concepts, and none is a property. One might say that something is long, but on seeing something else longer, the former becomes the shorter. One might say that something is forward, but when something shows up at its front, it becomes backward. If we judge things beautiful or not in their way, we greatly deviate from the truth [20]. When people predicate the feature of something, they always refer to its appearance. Lao-tzu pointed out that referring to appearance will undoubtedly be disturbed by relative relation of things so that the judgment of what is admissible is ambiguous or even absurd.

In Lao-tzu's point of view, the Zhi Dao theory of Confucius is far from the critical substance of things, which in turn distorts the true feature of things. In his refutation, Lao-tzu indicated that the problem of Confucius's theory lies in what to learn. Additionally, Lao-tzu questioned whether leaning what to be learned of Zhi Dao can really help one to be enlightened as well as whether it is possible for one to be enlightened by learning (imitating) what to learn. Confucius's what to learn, according to Lao-tzu's understanding, is a path through which the thinking pattern of scholars become incorporeal from corporeal. Lao-tzu once said:

Of those who have their heads and feet, and yet have neither minds nor ears, there are multitudes; while of those who have their bodies, and at the same time preserve that which has no bodily form or shape, there are really none [21].

Xianqian Wang proposed to construe the corporeal as man and the incorporeal as Dao [22]. But according to the 6th chapter of The Revolution of Heaven, the corporeal here means in general anything that has a shape rather than just man [23]. As in the 6th chapter of The Revolution of Heaven:

Fame is a possession common to all; we should not seek to have much of it. Benevolence and righteousness were as the lodging-houses of the former kings; we should only rest in them for a night, and not occupy them for long. If men see us doing so, they will have much to say against us. The 
perfect men of old trod the path of benevolence as a path which they borrowed for the occasion, and dwelt in Righteousness as in a lodging which they used for a night. Thus they rambled in the vacancy of Untroubled Ease, found their food in the fields of Indifference, and stood in the gardens which they had not borrowed [25].

Therefore, there are really none of those who have their bodies, and at the same time preserve that which has no bodily form or shape here actually means that corporeal things cannot coexist with incorporeal Dao perpetually, the former is only a temporary tabernacle of the latter. Fame here is about what is affirmable or not; Benevolence and righteousness here is about what is admissible or not, and both verdicts are imposed on corporeal things. The gap between corporeal entity and incorporeal Dao hinders man from enlightenment.

The challenge (argument) from the verdict that there are really none of those who have their bodies, and at the same time preserve that which has no bodily form or shape is a thorough denial to the theory on how to learn (imitate) of Confucius, especially when the verdict is set to a dynamic worldview. In the 5th chapter of Laozi:

The space between Heaven and Earth is just like a giant Tuo Yue (bellows): Empty it, it is not exhausted. Squeeze it and more comes out [25].

Tuo is like the Void, which includes everything in the world; and Yue is like the Primordial Qi, which derives everything in the world [26]. Lao-tzu pointed out that all things between heaven and earth change continuously, and the incorporeal Dao is eternally changeless while corporeal entity change constantly thus there are really none of those who have their bodies, and at the same time preserve that which has no bodily form or shape. I am in favor of Guoxiang's annotation here that those who masters in Zhi Dao never constrain themselves with established principles and that one deviates from the truth if he sticks to established principles and refuse to make a change $[27,28]$. In sharp contrast, the foundation of the theory on how to learn of Confucius is exactly to follow established principles. In Analects:

The Master said, "If a man keeps cherishing his old knowledge, so as continually to be acquiring new, he may be a teacher of others" [29].

This is Confucius's explanation to the validity of his theory on how to learn as well as why one can be enlightened through learning. Analects: With Selections from Traditional Commentaries quotes Huang Shisan's interpretation in Annotations of Analects that those aged are what (we) inherited from the ancient and are what have been established; those new are what belong to the present and happen recently [30]. In retrospect, Confucius advocated to learn from the records and living sages, both of which are established standards so that can be imitated or followed, and that is why they are described as established. But Lao-tzu was against this thesis of knowing things of today by knowing things of yesterday [31]. He refuted Confucius as in the 8th chapter of The Revolution of Heaven:

Those six writings are a description of the vestiges left by the former kings, but do not tell how they made such vestiges / authentic work; and what you, Sir, speak about are still only the vestiges. But vestiges are the prints left by the shoes - are they the shoes that produced them [32].

Here in Zhuangzi, Lao-tzu distinguished Dao from any other thing in the world by taking coupled examples of vestiges and what has left the vestiges, corporeal and incorporeal, and he also pointed out that corporeal things are changing continuously, and what's between corporeal an incorporeal can only be a temporary resident relation (incorporeal dwells in corporeal). Therefore, when taking a glimpse at the river of time, it is impossible to comprehend Dao of today by merely consulting experience and standards of yesterday. What Confucius advocated to learn and to imitate cannot help, either. Hence at this point, Lao-tzu had completely overturned the theory on what to learn of Confucius. Eventually in 9th chapter of The Heaven and Earth, Lao-tzu put forward his approach to Zhi Dao:

The regulation of courses (Zhi Dao) lies in the man himself. When he has forgotten external things, and have also forgotten the heavenly element in him, he may be named a man who have forgotten himself. The man who has forgotten himself is he of whom it is said that has become identified with Heaven [33]. 
Those who have the ability to regulate, and can forget external things as well as nature can be called have forgotten himself. Those who have forgotten himself are those who have become identified with Heaven. Cheng Xuanying concluded that only those who forget both external things and himself can comprehend the essence of Dao [34]. The problem of Confucius lies in his thesis of knowing things of today by knowing things of yesterday. In contrast with Confucius, Lao-tzu put forward a thesis of forgetting oneself by abandoning corporeal world so as to eliminate the obstacle resulted from aberrance in corporeal world over time in pursuing Dao.

\section{Conclusion}

The difference of Confucius and Lao-tzu in Zhi Dao basically lies in their respective comprehension of Dao. To Confucius, Dao means ethic, which is a set of standards that predicate whether or not our behaviors in ethical activities are appropriate [35]. Therefore, the essence of what to learn mentioned by Confucius is actually to learn what is admissible or inadmissible, affirmed or not, which in fact is a benchmark for measuring whether ethical activities are appropriate. And if ethical activities accord with this benchmark, people can be called Zhi Dao.

While to Lao-tzu, Dao is more like the Creator [36]. Lao-tzu himself confirmed the meaning of Dao through examples of contrary existence of corporeal and incorporeal nature, along with inconstant and constant things. Hence, the approach to Zhi Dao of Lao-tzu requires dealing with corporeal things that stands against Dao yet that every man confronts directly.

The record of the discussion about Zhi Dao between Confucius and Lao-tzu in Zhuangzi may not fully represent their original thoughts but somehow reveals the core of their debate, and also provides us with a new inspiration to rethink their thoughts and theories.

\section{References}

[1] Wendian Liu, et al. Zhuangzi, Additions and Corrections. Zhong Hua Book Company, 2015, p. 346.

[2] Shumin Wang, et al. Zhuangzi, Corrections and Annotations, 1st edition. Zhong Hua Book Company, 2007.

[3] Wendian Liu, et al. Zhuangzi, Additions and Corrections. Zhong Hua Book Company, 2015, p. 346.

[4] Wendian Liu, et al. Zhuangzi, Additions and Corrections. Zhong Hua Book Company, 2015, p. 346.

[5] Wendian Liu, et al. Zhuangzi, Additions and Corrections. Zhong Hua Book Company, 2015, p. 346.

[6] Shumin Wang, et al. Zhuangzi, Corrections and Annotations. Zhong Hua Book Company, 2015, p. 619-620.

[7] Wendian Liu, et al. Zhuangzi, Additions and Corrections. Zhong Hua Book Company, 2015, p. 486.

[8] Shumin Wang, et al. Zhuangzi, Corrections and Annotations. Zhong Hua Book Company, 2015, p. 436.

[9] Shude Cheng, et al. Analects, Annotations, 1st edition. Zhong Hua Book Company, 1990, p. 367.

[10] Shude Cheng, et al. Analects, Annotations. Zhong Hua Book Company, 1990, p. 417.

[11] Shude Cheng, et al. Analects, Annotations. Zhong Hua Book Company, 1990, p. 539-540.

[12] Shude Cheng, et al. Analects, Annotations. Zhong Hua Book Company, 1990, p. 417.

[13] Shude Cheng, et al. Analects, Annotations. Zhong Hua Book Company, 1990, p. 161.

[14] Shude Cheng, et al. Analects, Annotations. Zhong Hua Book Company, 1990, p. 163.

[15]Wendian Liu, et al. Zhuangzi, Additions and Corrections. Zhong Hua Book Company, 2015, p. 347. 
[16]Wendian Liu, et al. Zhuangzi, Additions and Corrections. Zhong Hua Book Company, 2015, p. 347.

[17]Wendian Liu, et al. Zhuangzi, Additions and Corrections. Zhong Hua Book Company, 2015, p. 348.

[18]Wendian Liu, et al. Zhuangzi, Additions and Corrections. Zhong Hua Book Company, 2015, p. 347.

[19]Ming Gao, et al. Laozi, Corrections and Annotations. Zhong Hua Book Company, 1996, p. 228-231.

[20]Ming Gao, et al. Laozi, Corrections and Annotations. Zhong Hua Book Company, 1996, p. 231.

[21]Wendian Liu, et al. Zhuangzi, Additions and Corrections. Zhong Hua Book Company, 2015, p. 347

[22]Xianqian Wang, et al. Zhuangzi, Collected Annotations, 2nd edition. Zhong Hua Book Company, 2012, p. 131

[23]Wendian Liu, et al. Zhuangzi, Additions and Corrections. Zhong Hua Book Company, 2015, p. 417

[24]Wendian Liu, et al. Zhuangzi, Additions and Corrections. Zhong Hua Book Company, 2015, p 418

[25]Ming Gao, et al. Laozi, Corrections and Annotations. Zhong Hua Book Company, 1996, p. 244-245.

[26]Ming Gao, et al. Laozi, Corrections and Annotations. Zhong Hua Book Company, 1996, p. 345.

[27]Wendian Liu, et al. Zhuangzi, Additions and Corrections. Zhong Hua Book Company, 2015, p. 348.

[28]Wendian Liu, et al. Zhuangzi, Additions and Corrections. Zhong Hua Book Company, 2015, p. 420.

[29] Shude Cheng, et al. Analects, Annotations. Zhong Hua Book Company, 1st edition, 1990, p. 94. [30] Shude Cheng, et al. Analects, Annotations. Zhong Hua Book Company, 1st edition, 1990, p. 94.

[31] Ming Gao, et al. Laozi, Corrections and Annotations. Zhong Hua Book Company, 1996, p. 288.

[32] Wendian Liu, et al. Zhuangzi, Additions and Corrections. Zhong Hua Book Company, 2015, p. 429.

[33]Wendian Liu, et al. Zhuangzi, Additions and Corrections. Zhong Hua Book Company, 2015, p. 384.

[34]Wendian Liu, et al. Zhuangzi, Additions and Corrections. Zhong Hua Book Company, 2015, p. 384.

[35] Shude Cheng, et al. Analects, Annotations. Zhong Hua Book Company, 1st edition, 1990, p. 232-237, p. 257-266.

[36]Ming Gao, et al. Laozi, Corrections and Annotations. Zhong Hua Book Company, 1996, p. 348-354. 